\title{
Calprotectin as a diagnostic tool for inflammatory bowel diseases (Review)
}

\author{
MARIANTHI CHATZIKONSTANTINOU ${ }^{1}$, PANAGIOTIS KONSTANTOPOULOS ${ }^{1}$, SPYROS STERGIOPOULOS $^{2}$, \\ KONSTANTINOS KONTZOGLOU ${ }^{3}$, CHRISTOS VERIKOKOS ${ }^{3}$, DESPINA PERREA ${ }^{1}$ and DIMITRIS DIMITROULIS ${ }^{3}$ \\ ${ }^{1}$ Laboratory of Experimental Surgery and Surgical Research N.S Christeas, National and Kapodistrian \\ University of Athens, Athens $11527 ;{ }^{2}$ Fourth Department of Surgery, Athens University Medical School, \\ Attikon University Hospital, Athens 12462; ${ }^{3}$ Second Department of Propedeutic Surgery, 'Laiko' General \\ Hospital, National and Kapodistrian University of Athens, Medical School, Athens 11527, Greece
}

Received May 16, 2016; Accepted August 29, 2016

DOI: 10.3892/br.2016.751

\begin{abstract}
Inflammatory bowel diseases (IBD) are chronic intestinal disorders caused by a number of factors, including external influences, intestinal microbiota and genetics. The two major clinically defined types of IBD are Crohn's disease and ulcerative colitis, each of which is characterized by relapses in the clinical course, thus patients must be under constant observation via regular endoscopies. As endoscopy, which has been used for direct evaluation and diagnosis of IBD, requires uncomfortable and expensive bowel preparation, a non-invasive test was required to reduce the number of patients undergoing unnecessary endoscopy. Calprotectin is a protein occurring in the cytosol of inflammatory cells and is released by the activation of leukocytes. As it is elevated and stable in the faeces of patients with IBD and can be reliably detected in faecal samples of $<5 \mathrm{~g}$, it may serve as an inexpensive, non-invasive diagnostic method for IBD. This is explored in the following review.
\end{abstract}

\section{Contents}

1. Introduction

2. IBD

3. Calprotectin concentration as a marker for IBD

4. Conclusion

Correspondence to: Miss Marianthi Chatzikonstantinou, Laboratory of Experimental Surgery and Surgical Research N.S Christeas, National and Kapodistrian University of Athens, Ag. Thoma 15b, Goudi, Athens 11527, Greece

E-mail:hmarianthi@gmail.com

Abbreviations: IBD, inflammatory bowel disease; CD, Crohn's disease; UC, ulcerative colitis; IL-2, interleukin-2; TCR, T-cell receptor; TNF, tumor necrosis factor; ESR, erythrocyte sedimentation rate; $\mathrm{CRP}, \mathrm{C}$ reactive protein; CDAI, Crohn's disease activity index; UCAI, ulcerative colitis activity index

Key words: calprotectin, inflammatory bowel disease, diagnostic marker

\section{Introduction}

Calprotectin was first described in 1980 (1), with its name referring to its calcium binding and anti-microbial actions $(2,3)$. It is found in the cytosol of inflammatory cells (4) accounting for $60 \%$ of cytosolic protein in neutrophils (5), but is also present at a lower concentration in monocytes and reactive macrophages (6). Calprotectin is released following activation of leukocytes, and due to its ability to inhibit zinc-dependent enzyme systems (2), it exerts bacteriostatic and fungistatic effects (6). In addition, calprotectin induces apoptosis in normal and cancer cells (7). Depending on the organ affected by inflammation, increased levels of calprotectin can be observed in the plasma, cerebrospinal fluid, synovial fluid, urine or faeces (8). It has been observed that the concentration of calprotectin in the faeces of healthy subjects, is approximately six times the concentration found in their plasma and in the presence of calcium, it withstands proteolytic degradation; in faeces, it is therefore stable at room temperature for up to seven days (9). Calprotectin can be reliably measured in faecal samples of $<5 \mathrm{~g}$. In addition, the protein's properties allow for the collection of a sample at home and potentially delayed transportation to the laboratory (9). Numerous studies have indicated that faecal calprotectin may represent an alternative marker of neutrophil influx into the bowel lumen (10). In line with this, increased faecal levels of calprotectin have been observed in inflammatory bowel diseases (IBD) $(9,11)$, colon cancer (12) and non-steroidal anti-inflammatory drug (NSAID) enteropathy $(13,14)$, suggesting that calprotectin is a sensitive, but non-specific marker of intestinal inflammation.

\section{IBD}

IBD are chronic intestinal disorders arising in the setting of complex interactions between host-derived and external elements, involving various aspects of the intestinal microbiota, the immune system, the genetic composition of the host and specific environmental factors (15), and which typically have a relapsing course (16). The two major clinically defined types of IBD are ulcerative colitis (UC) and Crohn's disease (CD), each of which may affect the entire colonic mucosa and 


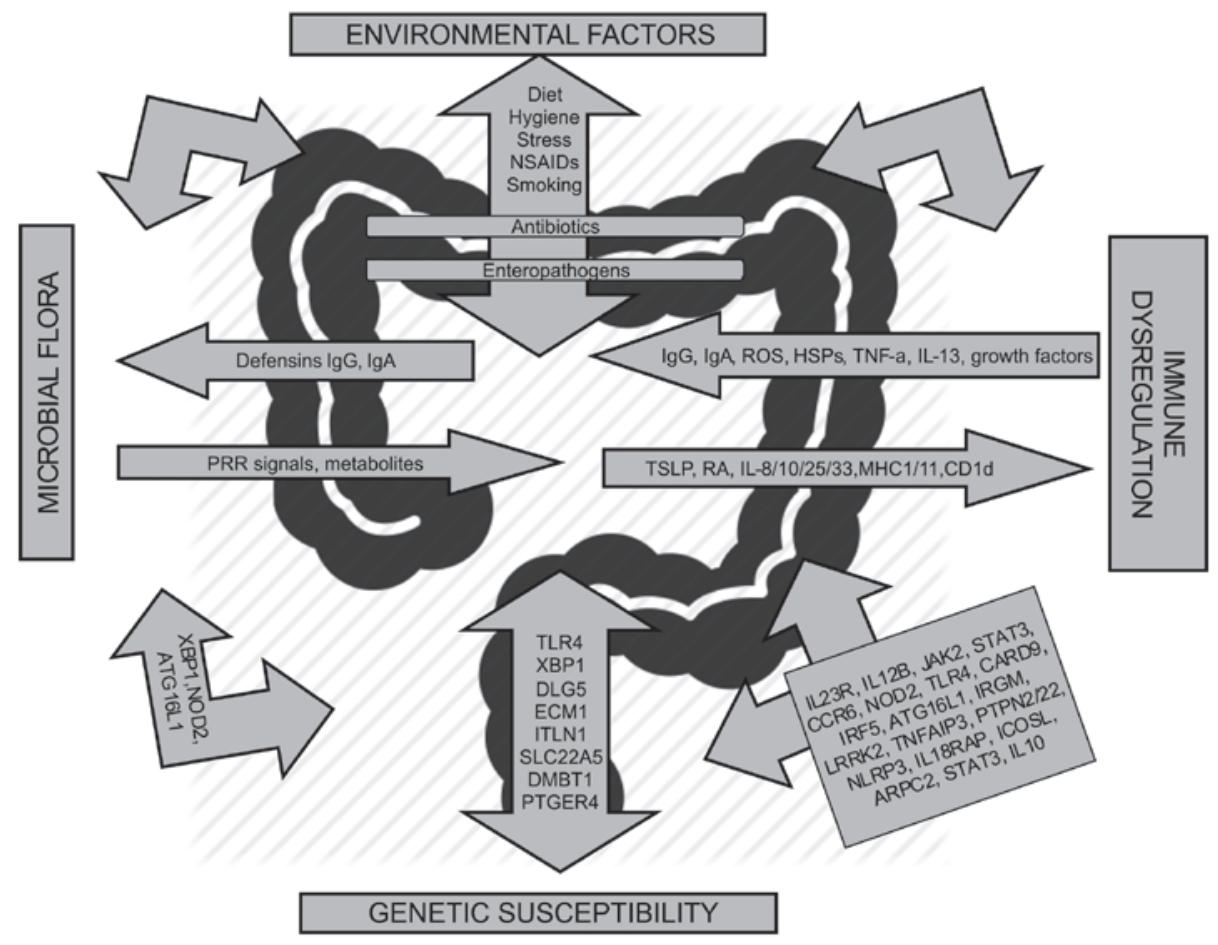

Figure 1. Molecular pathways associated with inflammatory bowel disease. Genes belonging to the same pathway are grouped in the same arrow. Genetic associations in Crohn's disease and ulcerative colitis are shown. Ig, immunoglobulin; TSLP, thymic stromal lymphopoietin; RA, retinoic acid; ROS, reactive oxygen species; NSAIDs, non-steroidal anti-inflammatory drugs; HSP, heat shock protein; PRR, pattern-recognition receptor; XBP1, X-box binding protein; NOD2, nucleotide-binding oligomerization domain-containing protein; ATG16L1, autophagy-related protein 16-1; TLR, Toll-like receptor; MHC, major histocompatibility complex; DLG5, discs large homologue 5; ECM1, extracellular matrix protein 1; ITLN1, interlactin 1; SLC22A5, solute carrier family 22 member 5; DMBT1, deleted in malignant brain tumors 1; PTGER4, prostaglandin E receptor 4; TNF-a, tumor necrosis factor alpha; IL, interleukin; JAK2, Janus kinase 2; STAT3, signal transducer and activator of transcription; CCR6, C-C-chemokine receptor type 6; NOD2, nucleotide-binding oligomerization domain-containing protein 2; CARD9, caspase recruitment domain-containing protein 9; IRF5, interferon regulatory factor 5; IRGM, immunity-related guanine triphosphatase family M protein; LRRK2, leucine-rich repeat kinase 2; TNFAIP3, TNF-a-induced protein 3; PTPN2, protein tyrosine phosphatase, non-receptor type 2; NLRP3, NACHT, LRR and PYD domains-containing protein 3; IL18RAP, Interleukin 18 receptor accessory protein; ICOSL, inducible T-cell co-stimulator ligand; ARPC2, actin related protein $2 / 3$ complex subunit 2 (15).

gastrointestinal tract, respectively, and is associated with an increased risk of colon cancer (15).

$\mathrm{CD}$ is a chronic inflammatory gastrointestinal tract disorder $(17,18)$. While no definitive therapy has been established (6), the main goal of IBD treatment is the lasting and effective suppression of the inflammatory response with the aim of achieving and maintaining clinical remission. However, sub-clinical inflammation of the intestinal wall may persist even after successful treatment and significantly contributes to the risk of relapse (16). It has been reported that among patients with medically induced remission, $30-60 \%$ show a relapse within 1 year (19) and at five years following diagnosis, $\sim 50 \%$ require surgery (20).

The exact etiology of IBD has remained elusive (16); however, IBD has been suggested to have a genetic basis and likely involves a response of the immune system to certain environmental agents (15). The role of environmental factors besides genetics in the pathogenesis of IBD has been evidenced by differences among monozygotic twins regarding their proneness towards developing IBD (21), as well as the development of IBD in immigrants in high-prevalence countries (22) and in countries undergoing rapid westernization (23). Experimental studies have reported the development of IBD-like enterocolitis in interleukin-2 (IL-2), IL-10 or T-cell receptor-mutant mice (24-26), and blockade of tumor necrosis factor- $\alpha$ was proven be an effective treatment for patients with $\mathrm{CD}$, which initiated a new field of research in the early 1990s (15). In addition, studies on the genetic basis of IBD (27) and a sequencing analysis of the intestinal microbiome (28) provided further insight into the pathophysiology of these conditions. A number of molecular pathways are involved in IBD, interfering both with genes of the immune system and the microbial flora. Immunoglobulins, tumor necrosis factors, and growth factors are among the factors involved in molecular pathways associated with the immune system (15). The molecular pathways involved in IBD are summarized in Fig. 1.

There are, however, polymorphisms in the following genes specific for CD: Nucleotide-binding oligomerization domain-containing protein, autophagy-related protein 16-1, interlactin 1, prostaglandin E receptor 4, C-C-chemokine receptor type 6, immunity-related guanine triphosphatase family M protein, NACHT,LRR and PYD domains-containing protein 3 and inducible T-cell co-stimulator ligand, whereas those specific for UC are extracellular matrix protein 1, actin related protein 2/3 complex subunit 2 and IL10 (15) (Fig. 1).

\section{Calprotectin concentration as a marker for IBD}

Numerous patients consider endoscopy for the direct evaluation and diagnosis of IBD; however, the bowel preparation required for this procedure is uncomfortable and expensive (29). Furthermore, a large proportion of patients with suspected 


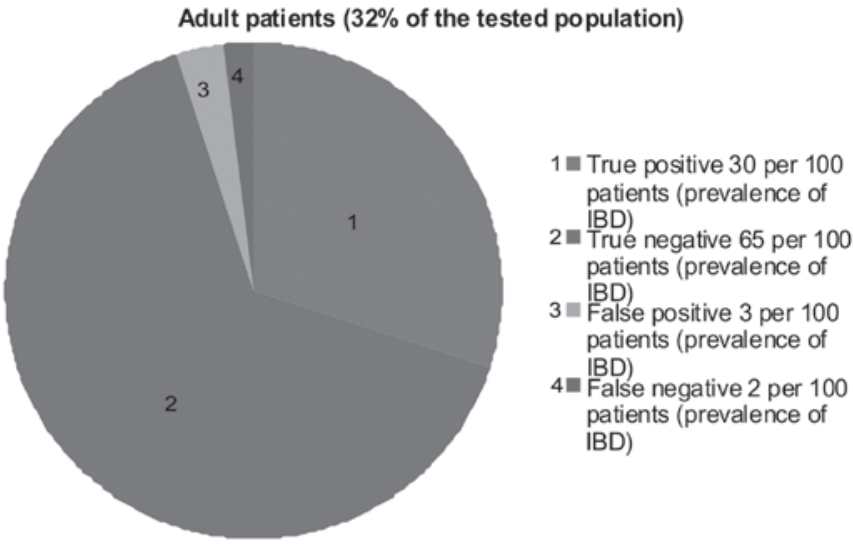

Children and teenage tatients ( $61 \%$ of the tested population)

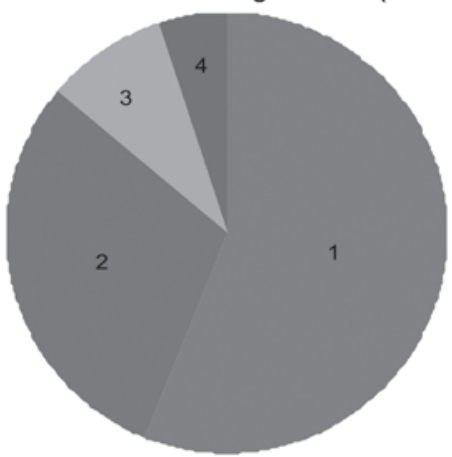

1 True positive 56 per 100 patients (prevalence of

IBD) patients (prevalence of patients 3. IBD) se positive 9 per 100 patients (prevalence of IBD)

- False negative 5 per 100 patients (prevalence of IBD)

Figure 2. Sensitivity of calprotectin screening. In a population of 100 adults with suspected IBD (and an overall mean prevalence of $32 \%$ ), 95\% of the samples correlated with the endoscopic evidence and faecal calprotectin screening would therefore reduce the number of adults requiring endoscopy by $67 \%$. In a population of 100 patients aged $<18$ years with suspected IBD (and an overall mean prevalence of $61 \%$ ), $86 \%$ of the samples correlated with the endoscopic evidence and faecal calprotectin screening would reduce the number of patients requiring endoscopy by $35 \%$ (33). IBD, inflammatory bowel diseases.

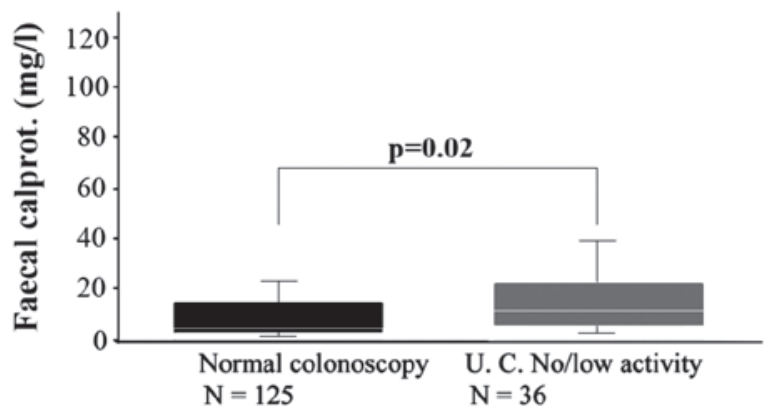

Figure 3. Association of calprotectin levels with endoscopically and histologically determined activity of 36 outpatients with U.C. The concentration of faecal calprotectin in these patients, who either had low-activity U.C or inactive U.C., as determined by endoscopy and histology, was significantly higher than that in 125 patients who were normal on colonoscopy. White lines indicate the median value, boxes the first and third quartile range and bars the standard deviation (30). U.C., ulcerative colitis.

IBD are negatively diagnosed by endoscopy, and a non-invasive test was therefore required to minimize the number of patients unnecessarily undergoing invasive endoscopy (10). Specifically, one third of all adults with bleeding-associated intestinal symptoms have no abnormalities on endoscopy,

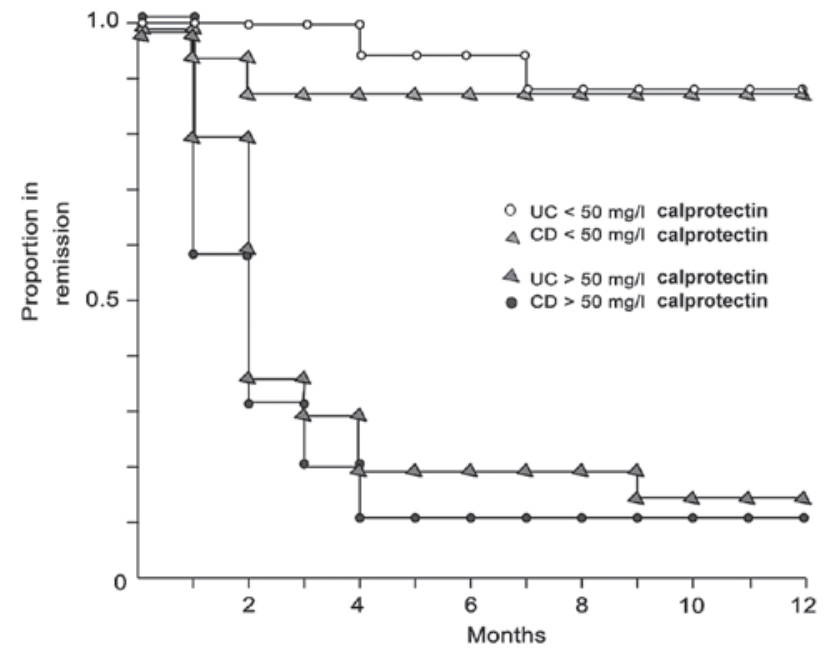

Figure 4. Kaplan-Meier survival curves for patients with IBD. A total of $58 \%$ of patients with $\mathrm{CD}$ and $51 \%$ of those with UC had relapsed during the one-year follow-up period. Receiver operator characteristic analysis revealed that faecal calprotectin levels of $50 \mathrm{mg} / 1$ (or $250 \mathrm{mg} / \mathrm{kg}$ ) predicted a relapse with $90 \%$ sensitivity and $83 \%$ specificity, indicating that the calprotectin test may be useful for adjustment of the medical treatment of IBD and to thereby reduce side effects and probably the development of secondary changes in the gastrointestinal tract of IBD patients (44). CD, Crohn's disease; UC, ulcerative colitis; IBD, inflammatory bowel diseases.

whilst only half of those with non-bleeding symptoms, such as diarrhoea, abdominal pain and weight loss are diagnosed with IBD based on endoscopy results.

In an effort to identify novel diagnostic markers for IBD, calprotectin was investigated. Early studies indicated an increase of calprotectin levels in patients with IBD (9), which was also correlated with endoscopic and histological evidence of inflammation (30-32). Since 2000, faecal calprotectin has been assessed in adult and paediatric populations, including patients with known inflammatory bowel disease on one side of the patient spectrum and healthy individuals on the other (33). As shown in Fig. 2, the calprotectin levels in $86 \%$ of paediatric faecal samples and $95 \%$ of samples from adults correlated with the endoscopic evidence, reflecting the high sensitivity of the test in all age groups.

Studies have indicated that faecal calprotectin may serve as a surrogate marker of neutrophil influx into the bowel lumen and therefore as a marker of intestinal inflammation, with a significant association with $\operatorname{IBD}(9,11)$, colon cancer $(12)$ and NSAID enteropathy $(13,14)$. These results suggested that calprotectin serves as a sensitive but non-specific marker of intestinal inflammation (34), a predictor for the severity of IBS in adults (35) and children (11) as well as relapse of IBS (36), and may be used for monitoring treatment responses (37).

Regarding UC, increased levels of calprotectin have been confirmed to be correlated with endoscopic results and histological grading of disease activity $(30,38)$. For instance, in a study on 36 outpatients, whose endoscopic and histological results showed low activity of UC, faecal calprotectin was significantly higher than that in 125 patients who were normal on colonoscopy (Fig. 3) (30).

Furthermore, due to the variable location and patchy distribution of $\mathrm{CD}$, it has been suggested that calprotectin as a diagnostic marker is more sensitive than endoscopy. 
Unlike UC, which exclusively affects the colon allowing for detection by endoscopic examination and subsequent histological analysis, CD may include areas of the small intestine, which are not always accessible by endoscopic examination and may only be detectable by capsule endoscopy (39). Therefore, due to the lack of histological findings (6), detection of inflammation in $\mathrm{CD}$ is difficult and laboratory parameters of inflammation are used. However, C-reactive protein and the erythrocyte sedimentation rate lack specificity or sensitivity and clinical indices of disease activity, such as the CD activity index, the UC activity index and the Harvey-Bradshaw activity index are associated with the patient's quality of life and well-being rather than the degree of mucosal inflammation (40-43).

Of note, faecal calprotectin can be utilized as an ideal initial marker for IBD, as its detection is cost-efficient and simple (6). A stool sample of $<5 \mathrm{~g}$ is required for analysis using a commercial enzyme-linked immunosorbent assay kit. In addition, calprotectin in faecal samples is stable at room temperature for up to seven days, which allows for self-sampling by patients at home and as well as convenience and reliability of laboratory detection.

However, controversy remains regarding the predictive value of faecal calprotectin in patients in remission. A study by Tibble et al (44) indicated that faecal calprotectin is associated with the risk of early relapse, with no difference between UC and CD (16,45), as shown by the Kaplan-Meier curves (Fig. 4).

\section{Conclusion}

Faecal calprotectin can be used as a cost-efficient and non-invasive method for IBD diagnosis. While this preliminary marker cannot replace endoscopy and histological analysis, it may be a reliable tool to support the diagnosis of IBD, to predict early relapse of IBD in patients with drug-induced remission and may also help to spare patients from unnecessary endoscopy when calprotectin levels are low.

\section{References}

1. Fagerhol MK, Dale I and Andersson T: A radioimmunoassay for a granulocyte protein as a marker in studies on the turnover of such cells. Bull Eur Physiopathol Respir 16: 273-282, 1980.

2. Steinbakk M,Naess-Andresen CF,Lingaas E, Dale I, Brandtzaeg P and Fagerhol MK: Antimicrobial actions of calcium binding leucocyte L1 protein, calprotectin. Lancet 336: 763-765, 1990.

3. Sohnle PG, Collins-Lech C and Wiessner JH: Antimicrobial activity of an abundant calcium-binding protein in the cytoplasm of human neutrophils. J Infect Dis 163: 187-192, 1991.

4. Røseth AG, Schmidt PN and Fagerhol MK: Correlation between faecal excretion of indium-111-labelled granulocytes and calprotectin, a granulocyte marker protein, in patients with inflammatory bowel disease. Scand J Gastroenterol 34: 50-54, 1999.

5. Fagerhol MK, Andersson KB, Naess Andresen CF, Brandtzaeg P and Dale I: Calprotectin (the L1 leucoyte protein). In: Stimulus Response Coupling: The Role of Intracellular Calcium Binding Proteins. Smith VL and Dedman JR (eds). CRC Press Inc., Boca Raton, FL, pp187-210, 1990.

6. Gaya DR and Mackenzie JF: Faecal calprotectin: A bright future for assessing diseaseactivity in Crohn's disease. QJM 95: 557-558, 2002

7. Yiu S, Mikami M and Yamazaki M: Induction of apoptoic cell death in mouse lymphoma and human leukaemia cell lines by a calcium-binding protein complex, calprotectin, derived from inflammatory peritoneal exudate cells. J Leukoc Biol 336 $763-765,1995$
8. Johne B, Fagerhol MK, Lyberg T, Prydz H, Brandtzaeg P, Naess-Andresen CF and Dale I: Functional and clinical aspects of the myelomonocyte protein calprotectin. Mol Pathol 50: 113-123, 1997.

9. Røseth AG, Fagerhol MK, Aadland E and Schjønsby H: Assessment of the neutrophil dominating protein calprotectin in feces. A methodologic study. Scand J Gastroenterol 27: 793-798, 1992.

10. Lasson A, Kilander A and Stotzer PO: Diagnostic yield of colonoscopy based on symptoms. Scand J Gastroenterol 43: 356-362, 2008.

11. Bunn SK, Bisset WM, Main MJ and Golden BE: Fecal calprotectin as a measure of disease activity in childhood inflammatory bowel disease. J Pediatr Gastroenterol Nutr 32: 171-177, 2001

12. Røseth AG, Kristinsson J, Fagerhol MK, Schjønsby H, Aadland E, Nygaard K and Roald B: Faecal calprotectin: A novel test for the diagnosis of colorectal cancer? Scand J Gastroenterol 28: 1073-1076, 1993

13. Meling TR, Aabakken L, Røseth A and Osnes M: Faecal calprotectin shedding after short-term treatment with non-steroidal anti-inflammatory drugs. Scand J Gastroenterol 31: 339-344, 1996.

14. Tibble JA, Sigthorsson G, Foster R, Scott D, Fagerhol MK, Roseth A and Bjarnason I: High prevalence of NSAID enteropathy as shown by a simple faecal test. Gut 45: 362-366, 1999.

15. Kaser A, Zeissig S and Blumberg RS: Inflammatory bowel disease. Annu Rev Immunol 28: 573-621, 2010.

16. Riley SA, Mani V, Goodman MJ, Dutt S and Herd ME: Microscopic activity in ulcerative colitis: What does it mean? Gut 32: 174-178, 1991

17. Barton JR, Gillon S and Ferguson A: Incidence of inflammatory bowel disease in Scottish children between 1968 and 1983; marginal fall in ulcerative colitis, three-fold rise in Crohn's disease. Gut 30: 618-622, 1989.

18. Armitage E, Drummond H, Ghosh S and Ferguson A: Incidence of juvenile-onset Crohn's disease in Scotland. Lancet 353: 1496-1497, 1999.

19. Greenberg GR, Feagan BG, Martin F, Sutherland LR, Thomson AB, Williams CN, Nilsson LG and Persson T; Canadian Inflammatory Bowel Disease Study Group: Oral budesonide as maintenance treatment for Crohn's disease: A placebo-controlled, dose-ranging study. Gastroenterology 110: 45-51, 1996.

20. Rutgeerts PJ: Prevention of early recurrence of Crohn's disease after ileal resection with ileocolic anastomosis. Eur J Gastroenterol Hepatol 6: 113-116, 1994.

21. Halme L,Paavola-Sakki P, Turunen U,Lappalainen M, Farkkila M and Kontula K: Family and twin studies in inflammatory bowel disease. World J Gastroenterol 12: 3668-3672, 2006.

22. Tsironi E, Feakins RM, Probert CS, Rampton DS and Phil D: Incidence of inflammatory bowel disease is rising and abdominal tuberculosis is falling in Bangladeshis in East London, United Kingdom. Am J Gastroenterol 99: 1749-1755, 2004.

23. Thia KT, Loftus EV Jr, Sandborn WJ and Yang SK: An update on the epidemiology of inflammatory bowel disease in Asia. Am J Gastroenterol 103: 3167-3182, 2008.

24. Sadlack B, Merz H, Schorle H, Schimpl A, Feller AC and Horak I: Ulcerative colitis-like disease in mice with a disrupted interleukin-2 gene. Cell 75: 253-261, 1993.

25. Kühn R, Löhler J, Rennick D, Rajewsky K and Muller W: Interleukin-10-deficient mice develop chronic enterocolitis. Cell 75: 263-274, 1993.

26. Mombaerts P, Mizoguchi E, Grusby MJ, Glimcher LH, Bhan AK and Tonegawa S: Spontaneous development of inflammatory bowel disease in T cell receptor mutant mice. Cell 75: 274-282, 1993.

27. Gregersen PK and Olsson LM: Recent advances in the genetics of autoimmune disease. Annu Rev Immunol 27: 363-391, 2009.

28. Peterson DA, Frank DN, Pace NR and Gordon JI: Metagenomic approaches for defining the pathogenesis of inflammatory bowel diseases. Cell Host Microbe 3: 417-427, 2008.

29. Ristvedt SL, McFarland EG, Weinstock LB and Thyssen EP: Patient preferences for CT colonography, conventional colonoscopy, and bowel preparation. Am J Gastroenterol 98: 578-585, 2003.

30. Røseth AG, Aadland E, Jahnsen J and Raknerud N: Assessment of disease activity in ulcerative colitis by faecal calprotectin, a novel granulocyte marker protein. Digestion 58: 176-180, 1997.

31. Tibble J, Teahon K, Thjodleifsson B, Roseth A, Sigthorsson G, Bridger S, Foster R, Sherwood R, Fagerhol M and Bjarnason I: A simple method for assessing intestinal inflammation in Crohn's disease. Gut 47: 506-513, 2000. 
32. Costa F, Mumolo MG, Bellini M, Romano MR, Ceccarelli L, Arpe P, Sterpi C, Marchi S and Maltinti G: Role of faecal calprotectin as non-invasive marker of intestinal inflammation. Dig Liver Dis 35: 642-647, 2003.

33. van Rheenen PF, Van de Vijver E and Fidler V: Faecal calprotectin for screening of patients with suspected inflammatory bowel disease: Diagnostic meta-analysis. BMJ 341: c3369, 2010.

34. von Roon AC, Karamountzos L, Purkayastha S, Reese GE, Darzi AW, Teare JP, Paraskeva P and Tekkis PP: Diagnostic precision of fecal calprotectin for inflammatory bowel disease and colorectal malignancy. Am J Gastroenterol 102: 803-813, 2007.

35. Limburg PJ, Ahlquist DA, Sandborn WJ, Mahoney DW, Devens ME, Harrington JJ and Zinsmeister AR: Fecal calprotectin levels predict colorectal inflammation among patients with chronic diarrhea referred for colonoscopy. Am J Gastroenterol 95: 2831-2837, 2000.

36. Costa F, Mumolo MG, Ceccarelli L, Bellini M, Romano MR, Sterpi C, Ricchiuti A, Marchi S and Bottai M: Calprotectin is a stronger predictive marker of relapse in ulcerative colitis than in Crohn's disease. Gut 54: 364-368, 2005.

37. Røseth AG, Aadland E and Grzyb K: Normalization of faecal calprotectin: A predictor of mucosal healing in patients with inflammatory bowel disease. Scand J Gastroenterol 39: 1017-1020, 2004

38. Bunn SK, Bisset WM, Main MJ, Gray ES, Olson S and Golden BE: Fecal calprotectin: Validation as a noninvasive measure of bowel inflammation in childhood inflammatory bowel disease. J Pediatr Gastroenterol Nutr 33: 14-22, 2001.
39. Fireman Z, Mahajna E, Broide E, Shapiro M, Fich L, Sternberg A, Kopelman Y and Scapa E: Diagnosing small bowel Crohn's disease with wireless capsule endoscopy. Gut 52: 390-392, 2003.

40. Crama-Bohbouth G, Pena AS, Biemond I, Verspaget HW, Blok D, Arndt JW, Weterman IT, Pauwels EK and Lamers CB: Are activity indices helpful in assessing active intestinal inflammation in Crohn's disease? Gut 30: 1236-1240, 1989.

41. Modigliani R, Mary JY, Simon JF, Cortot A, Soule JC, Gendre JP and Rene E: Clinical, biological, and endoscopic picture of attacks of Crohn's disease. Evolution on prednisolone. Groupe d'Etude Thérapeutique des Affections Inflammatoires Digestives. Gastroenterology 98: 811-818, 1990.

42. Cellier C, Sahmoud T, Froguel E, Adenis A, Belaiche J, Bretagne JF, Florent C, Bouvry M, Mary JY and Modigliani R: Correlations between clinical activity, endoscopic severity, and biological parameters in colonic or ileocolonic Crohn's disease. A prospective multicentre study of 121 cases. The Groupe d'Etudes Thérapeutiques des Affections Inflammatoires Digestives. Gut 35: 231-235, 1994

43. Biancone L, De Nigris F, Del Vecchio Blanco G, Monteleone I, Vavassori P, Geremia A and Pallone F: Review article: Monitoring the activity of Crohn's disease. Aliment Pharmacol Ther 16 (Suppl 4): 29-33, 2002.

44. Tibble JA, Sigthorsson G, Bridger S, Fagerhol MK and Bjarnason I: Surrogate markers of intestinal inflammation are predictive of relapse in patients with inflammatory bowel disease. Gastroenterology 119: 15-22, 2000.

45. Modigliani R: Endoscopic management of inflammatory bowel disease. Am J Gastroenterol 89: S53-S65, 1994. 